\title{
Beneficial effects of
}

nasal high flow oxygen

therapy after weaning

from non-invasive

ventilation: A

prospective

observational study

BY TAKUYA KURAZUMI, TAKESHI SUZUKI, RIE WAKAMIYA, KIKUKO SUGA, YOSHIHISA MORITA, JUNICHI MASUDA,SHIZUKO KOSUGI, NOBUYUKI KATORI, HIROSHI MORISAKI

\section{Abstract}

It remains unknown whether application of nasal high flow (NHF) is effective after liberation from non-invasive ventilation (NIV). This study was aimed at investigating the effect of NHF in patients ready for weaning from NIV.

With institutional ethic committee approval, patients receiving NIV due to hypoxemic respiratory failure for more than 24 hours were enrolled. After passing the weaning criteria with continuous positive airway pressure (CPAP) mode [fraction of inspiratory oxygen $\left(\mathrm{FIO}_{2}\right) \leqq 0.5$, 
positive end expiratory pressure (PEEP) $\left.4 \mathrm{cmH}_{2} \mathrm{O}\right]$, patients received NHF (Flow $50 \mathrm{~L} / \mathrm{min}, \mathrm{FIO}_{2} \leqq 0.5$ ) immediately after liberation from NIV. Before the initiation of the study, eight sequential patients who received oxygen via face mask after NIV treatment, served as the historical control. Respiratory parameters [partial pressure of arterial oxygen $\left(\mathrm{PaO}_{2}\right)$ to $\mathrm{FIO}_{2}$ ratio (P/F ratio), respiratory rate (RR)] 1 hour after liberation from NIV were evaluated with those during NIV as the primary outcome. The frequency of rescue NIV therapy, intubation, and respiratory failure were also recorded.

Nine eligible patients received NHF therapy after liberation from NIV. $\mathrm{P} / \mathrm{F}$ ratio and RR did not change significantly compared with those during NIV (231 \pm 43.6 versus $250.7 \pm 34.2 \mathrm{mmHg}, 20.8 \pm 2.3$ versus 21 $\pm 1.6 / \mathrm{min}$ ), while $\mathrm{P} / \mathrm{F}$ ratio decreased significantly in the historical control group (194.3 \pm 20.1 versus $255.9 \pm 58.1 \mathrm{mmHg}, \mathrm{p}=0.013)$. Rescue NIV therapy, intubation, and respiratory failure never occurred in the NFH group, although two patients received NIV rescue therapy, of whom one was intubated in the historical control.

NHF after liberation from NIV might be effective in patients recovering from hypoxemic respiratory failure.

Registration number: UMINoooo14133 (UMIN-CTR)

Key words: hypoxemic respiratory failure, weaning, non-invasive ventilation, nasal high flow oxygen therapy, weaning failure, rescue therapy

\section{Introduction}

Non-invasive ventilation (NIV) has been recognized as effective therapy in improving gas exchange while reducing dyspnea in patients with not only hypercapnic but also hypoxemic respiratory failure. $(1,2)$ Previous studies have shown that NIV can treat respiratory failure without invasive mechanical ventilation, (3) avert the need for re-intubation after 
extubation in patients with risk factors, (4) and facilitate weaning from invasive ventilator support in medical patients predominantly with chronic obstructive pulmonary disease (COPD). (5) Contrary to these beneficial effects of NIV, there are some concerns regarding difficulties of NIV management. NIV prevents early mobilization, causes gastric distension, inhibits communication and oral intake, is poorly tolerated in some patients, and associated with facial injuries especially when the duration of NIV management is prolonged. (6) Thus, liberation from NIV as early as possible is one of the major goals in managing respiratory failure under NIV application. However, some patients develop respiratory failure after weaning from NIV to oxygen face mask even though the final positive end expiratory pressure (PEEP) level is at a minimum, which suggest that bridging therapy from NIV to face mask might be necessary for some patients.

Nasal high flow (NHF) oxygen therapy, which is well established in neonates and has recently been used in adult populations, (7) can deliver high flow humidified, blended air and oxygen up to $60 \mathrm{~L} / \mathrm{min}$ via widebore nasal cannula at a prescribed fraction of inspiratory oxygen $\left(\mathrm{FIO}_{2}\right)$.

(8) Given that the beneficial effects of NHF, such as improving oxygenation, reducing work of breathing, and facilitating secretion clearance, have been reported in recent studies, (9-11) NHF might be useful to wean patients from NIV to oxygen face mask efficiently and safely. However, there are few studies which have examined the effects of NHF on respiratory parameters through comparison with those of NIV, and evaluated the efficacy of NHF after liberation from NIV.

In this study, we examined the effect of NHF application after liberation from NIV management, compared with the historical control group in which patients received oxygen face mask after weaning from NIV.

\section{Materials and Methods}

This prospective, observational study was conducted in our 8-bed intensive care unit (ICU) of Kawasaki Municipal Hospital in Japan to 
investigate the effect of NHF on respiratory parameters in patients weaned from NIV during the period from September 2012 to March 2013. The protocol was approved by the regional ethics committee, which waived informed consent, since this study was observational in nature, and all procedures were established as routine practices in our ICU.

Patients receiving NIV through full face mask for more than 24 hours due to hypoxemic respiratory failure were screened for eligibility in this study, and all patients who met all the following inclusion criteria were enrolled in this study: (1) partial pressure of arterial oxygen $\left(\mathrm{PaO}_{2}\right)$ to $\mathrm{FIO}_{2}$ ratio (P/F ratio) more than $200 \mathrm{mmHg}$ with positive end expiratory pressure (PEEP) of $5 \mathrm{~cm}$ of water or less; (2) respiratory rate (RR) less than 30 breathes per min (bpm) with pressure support of $5 \mathrm{~cm}$ of water or less; (3) pH of blood gas analysis more than 7.35; (4) hemodynamic stability without vasopressor therapy; (5) adequate conscious level and cough reflex; (6) no agitation. Patients younger than 18 years old or with Glasgow Coma Scale less than 14 or with body mass index (BMI) more than 30 were excluded from this study.

As a historical control group, eight consecutive patients under NIV management because of hypoxemic respiratory failure, who were ready for weaning from NIV, were chosen before the initiation of this study. They received oxygen face mask therapy after liberation from NIV as standard care in our ICU.

NIV was delivered for all patients using the same device (BiPAP Vision, Respironics, USA). In patients who met all the inclusion criteria, the respiratory setting of NIV was changed to continuous positive airway pressure (CPAP) mode with PEEP of $4 \mathrm{cmH}_{2} \mathrm{O}$ and $\mathrm{FIO}_{2}$ equal to or less than 0.5. NIV was interrupted, and humidified high-flow oxygen via NHF system (Optiflow with MR880 humidifier, Fisher \& Paykel Healthcare, Auckland, New Zealand) was delivered through a wide-bore nasal cannula at the following setting; gas flow $5 \mathrm{O} \mathrm{l} / \mathrm{min}$ and $\mathrm{FIO}_{2}$ equal to or less than 0.5 , if patients passed all the following criteria, described below, 1hour after changing the respiratory setting of NIV: (1) P/F ratio 
more than $200 \mathrm{mmHg}$; (2) RR less than $30 \mathrm{bpm}$; (3) pH of blood gas analysis more than 7.35 ; (4) hemodynamic stability without vasopressor therapy; (5) adequate conscious level and cough reflex; (6) no agitation. The setting of NHF was not changed until 1hour after the initiation of NHF therapy if patients could maintain oxygen saturation by pulse oximetry $\left(\mathrm{SpO}_{2}\right)$ more than $92 \%$ and a RR less than $35 \mathrm{bpm}$. The setting of NHF was adjusted by the attending physician 1 hour after the initiation of NHF therapy to achieve $\mathrm{SpO}_{2}$ more than $93 \%$ and respiratory rate less than $30 \mathrm{bpm}$. Patients were weaned from NHF therapy by reducing gas flow rate gradually. NHF therapy was considered successful if the patients were weaned from NHF therapy without respiratory failure as defined below, rescue NIV therapy, and intubation for 24 hours.

In the historical control group, the weaning from NIV was performed in the same way as the NHF therapy group. They received standard face mask oxygen therapy (flow $30 \mathrm{l} / \mathrm{min}$ and $\mathrm{FIO}_{2}$ equal to or less than 0.5) instead of NHF immediately after the interruption of NIV. After weaning from NIV, the management of the patient was determined by the attending physician.

Patients were immediately intubated if any of the following immediate intubation criteria were present: (1) respiratory or cardiac arrest; (2) respiratory pauses with loss of consciousness or gasping for air; (3) uncontrolled agitation; (4) massive aspiration; (5) the inability to remove respiratory secretions; (6) severe hemodynamic instability unresolved by fluids and vasoactive agents. If patients developed respiratory failure, the physician in charge of the patient was allowed to use NIV for rescue therapy at any time. NIV was delivered through full face mask and adjusted to keep $\mathrm{SpO}_{2}$ equal to or more than $93 \%$ and respiratory rate less than $30 \mathrm{bpm}$. Respiratory failure was defined as the presence of at least one of the following criteria: (1) severe hypoxemia with $\mathrm{SpO}_{2}$ less than $92 \%$ or $\mathrm{PaO}_{2}$ less than $70 \mathrm{OmmHg}$ at $\mathrm{FIO}_{2}$ of 0.5 or more (2) RR greater than $35 \mathrm{bpm}$; (3) respiratory acidosis [arterial $\mathrm{pH}<7.3$ with 
partial pressure of arterial carbon dioxide $\left(\mathrm{PaCO}_{2}\right)>50 \mathrm{~mm} \mathrm{Hg];} \mathrm{(4)}$ clinical signs of respiratory muscle fatigue such as use of accessory muscle and paradoxical motion of the abdomen; (5) inability to remove secretions; (6) severe dyspnea. In case of respiratory failure persisting for more than 4 hours without improvement after NIV application, patients were to be strongly considered for intubation.

Demographic data, diagnosis, sequential organ failure assessment (SOFA) score at ICU admission, and duration of NIV were recorded at the enrollment of the study. Blood pressure, heart rate, $\mathrm{RR}$ and $\mathrm{SpO}_{2}$ were monitored continuously. Blood gases were analyzed every morning at $7 \mathrm{am}$, just before the interruption of NIV, 1hour after the initiation of NHF therapy, and at any time if indicated. In the historical control group, the last blood gas analysis data before liberation from NIV and the first data after oxygen mask therapy were extracted from medical records. Duration of NHF therapy, the rate of rescue NIV therapy and intubation, the frequency of respiratory failure, and the length of ICU stay after the first liberation from NIV were also recorded. Furthermore, each patient was asked which device was more comfortable, NIV with full face mask or NHF with a wide-bore nasal cannula, after completion of the study in the NHF group.

Primary end point was the change of respiratory parameters, including $\mathrm{P} / \mathrm{F}$ ratio and RR, 1 hour after initiation of NHF or oxygen mask compared with those during NIV. Secondary end points were the rate of rescue NIV therapy and intubation, the frequency of respiratory failure, the duration of NHF therapy, the length of ICU stay after weaning from NIV, and acceptability of NHF therapy compared with NIV.

Results were presented as mean $\pm \mathrm{SD}$ for variables with a normal distribution, or medians and interquartile range for variables with a nonnormal distribution, and compared with Student's t test or MannWhitney U test as appropriate. Categorical variables were compared with Fisher's exact test. A p-value less than 0.05 was considered as statistically significant. 


\section{Results}

All patients under NIV management, who were ready for weaning, were screened for eligibility over the study period. Nine patients, who passed the inclusion criteria, participated in the study overall. Clinical characteristics and demographic data at admission to ICU are summarized in table1. Duration of NIV ranged from 2 to 6 days. All nine patients received NHF therapy immediately after interruption of NIV, and the respiratory setting was not changed until the first blood sampling, 1 hour after initiation of NHF in all patients.

In the historical control group, who received oxygen mask therapy after interruption of NIV management, $\mathrm{P} / \mathrm{F}$ ratio decreased significantly compared with that just before liberation from NIV therapy $(194.3 \pm 20.1$ versus $255.9 \pm 58.1 \mathrm{mmHg}, \mathrm{p}=0.013$; table 2 ). On the other hand, $\mathrm{P} / \mathrm{F}$ ratio did not change significantly in nine patients who received NHF therapy immediately after weaning from NIV as shown in table 2 (231 \pm 43.6 versus $250.7 \pm 34.2 \mathrm{mmHg}, \mathrm{p}=0.367$ ). Respiratory rate after initiation of NHF or oxygen mask was also comparable with that during NIV (table 2).

Although two of eight patients in the historical control group required rescue NIV therapy again due to development of respiratory failure, of whom one patient was intubated after all, no patient developed respiratory failure or received NIV rescue therapy after initiation of NHF therapy in the NHF group. However, there was no significant difference between both groups regarding the rate of rescue NIV therapy $(\mathrm{p}=0.206)$. The duration of NHF therapy was 2 (1 to 3.25) days, and the length of ICU stay after liberation from NIV in the NHF group was not different significantly from that of the historical control group \{4 (3 to 5.25 ) versus 2 ( 2 to 4 ) days, $p=0.124\}$. Eight of nine patients who received NHF therapy after NIV management preferred NHF therapy to NIV.

\section{Discussion}


Our study demonstrated that NHF therapy after weaning from NIV is effective in maintaining sufficient oxygenation compared with oxygen face mask therapy in the historical control group, in which $\mathrm{P} / \mathrm{F}$ ratio decreased significantly after liberation from NIV and two patients received NIV rescue therapy after all. These results suggest that the weaning strategy from NIV through NHF application may be safe and effective in terms of that NHF could maintain sufficient oxygenation and prevent respiratory failure, which develops after liberation from NIV therapy.

In this study, $\mathrm{P} / \mathrm{F}$ ratio, representing the oxygenation status, was maintained in the NHF therapy group after weaning from NIV, while oxygen face mask therapy could not maintain oxygenation level compared to CPAP with PEEP level of $4 \mathrm{cmH}_{2} \mathrm{O}$. This result indicates that minimum PEEP level of $4 \mathrm{cmH}_{2} \mathrm{O}$ in NIV device contributes to oxygenation and NHF with $50 \mathrm{l} / \mathrm{min}$ flow rate can generate the same PEEP level. Previous studies have reported that NHF can produce PEEP dependent on flow rate, (12) which may improve ventilation perfusion matching and oxygenation. Although the actual PEEP level generated by NHF in this study is uncertain, to our knowledge, this is the first study which examined the effect of NHF on respiratory parameters compared with CPAP mode of NIV, and showed that $50 \mathrm{l} / \mathrm{min}$ flow rate of NHF had comparable effects on oxygenation with $4 \mathrm{cmH}_{2} \mathrm{O}$ PEEP level.

Furthermore, no patients weaned from NIV to NHF in this study developed respiratory failure or required rescue NIV therapy or intubation, while two patients in the historical control group required NIV again due to respiratory failure after weaning from NIV. Although a further study is warranted, this result implies the effectiveness of the weaning strategy from NIV management through NHF application.

Recently, data are accumulating which show the beneficial effects of NHF oxygen therapy not only in premature infants, (13) but also in adult respiratory failure. (7) In observational studies, NHF application in hypoxic respiratory failure patients has been reported to improve 
oxygenation, reduce respiratory rate and attenuate respiratory fatigue, compared to high flow face mask oxygen therapy. (14) A recent small randomized trial, (15) which included 60 patients not requiring mechanical ventilator support, with mild to moderate hypoxic respiratory failure, demonstrated that NHF therapy could reduce the rate of worsening respiratory failure compared with face mask oxygen therapy, although P/F ratio wasn't different significantly between groups. Another randomized trial, (16) which compared NFH therapy and high flow face mask therapy, has shown that NHF improved patient's tolerance even though there was no significant difference regarding respiratory parameters. While it remains to be clarified whether NHF oxygen therapy is actually superior to high flow oxygen mask therapy in management of respiratory failure, some mechanisms by which NHF could contribute to improvement of gas exchange should be considered. PEEP generated by NHF therapy could play a major role for improvement of oxygenation. The level of PEEP produced by NHF therapy has been reported to be affected by various factors, such as whether breathing is with open or closed mouth, (8) patient's sex, (17) and delivered flow rate. (12) The PEEP effect delivered by NHF could contribute to expansion of lung volume through recruitment of atelectasis, (18) reduction of work of breathing, (19) and improvement of ventilation-perfusion ratio, leading to improved respiratory condition. Reduction of dead space is also one of the possible mechanisms for clinical benefits of NHF. (19) The high flow rate generated by NHF system could wash-out expired $\mathrm{CO}_{2}$ from the upper airway, which can reduce rebreathing of $\mathrm{CO}_{2}$ and increase $\mathrm{FIO}_{2}$ which patients actually inspire. This beneficial effect may be quite outstanding, especially in hypercapnic respiratory failure such as COPD. Furthermore, NHF is likely to be better tolerated than face mask, improving patient adherence to oxygen therapy and treatment effectiveness. (16) Face mask may cause discomfort through difficulties of oral intake and communication, (20) which could prevent effective continuous oxygen therapy. In this study, all patients tolerated NHF well, and almost all of them described NHF as more comfortable than NIV through full face mask. 
There are several limitations to interpreting the data herein. First, this is not a randomized controlled trial, but an observational study which included only nine patients. It is unknown whether an application of NHF after liberation from NIV management could reduce the frequency of pulmonary complications, respiratory failure and mechanical ventilator support, which should be evaluated in large randomized controlled trials in the future. However, no patients who received NHF therapy after liberation from NIV required rescue NIV therapy, while two patients in the historical control group needed rescue NIV. Second, our results might not be applicable to other type of diseases such as pneumonia and chronic obstructive pulmonary disease, since almost all patients were post-cardiovascular surgery patients with cardiac dysfunction. Finally, we evaluated the effect of NHF with $50 \mathrm{l} / \mathrm{min}$ flow rate on respiratory parameters, compared with CPAP mode with 4 $\mathrm{cmH}_{2} \mathrm{O}$ PEEP level in this study. Thus, whether NHF therapy would be comparable with higher PEEP levels is unknown. In the study evaluating the efficacy of NHF in preterm infants after extubation, NHF therapy has been reported to have similar efficacy and safety to nasal CPAP with 7 $\mathrm{cmH}_{2} \mathrm{O}$ PEEP. (21) Further study is warranted to examine the degree of PEEP level at which patients could wean from NIV to NHF therapy in adult patients.

\section{Conclusion}

In this study, NHF with $50 \mathrm{l} / \mathrm{min}$ flow rate was found to have comparable effects with $4 \mathrm{cmH}_{2} \mathrm{O}$ PEEP level of CPAP mode regarding oxygenation, which suggests NHF might be effective and safe for preventing respiratory failure after weaning from NIV. Further investigation is necessary to establish the beneficial effects of NHF after liberation from NIV management.

\section{References}

1. Brochard L, Mancebo J, Wysocki M, Lofaso F, Conti G, Rauss A, et al. 
Noninvasive ventilation for acute exacerbation of chronic obstructive pulmonary disease. N Engl J Med 1995;333(13):817-22.

2. Peter JV, Moran JL, Phillips-Hughes J, Graham P, Bersten AD. Effect of non-invasive positive pressure ventilation (NIPPV) on mortality in patients with acute cardiogenic pulmonary oedema: a meta-analysis. Lancet 2006;367(9517):1155-63.

3. Nava S, Navalesi P, Conti G. Time of non-invasive ventilation. Intensive Care Med 2006;32(3):361-70.

4. Ferrer M, Valencia M, Nicolas LM, Bernadich O, Badia JR, Torres A. Early noninvasive ventilation averts extubation failure in patients at risk. Am J Respir Crit Care Med 2006;173(2):164-70.

5. Ferrer M, Esquinas A, Arancibia F, Bauer TT, Gonzalez G, Carrillo A, et al. Noninvasive ventilation during persistent weaning failure. Am J Respir Crit Care Med 2003;168(1):70-6.

6. Gregoretti C, Confalonieri M, Navalesi P, Squadrone V, Frigerio P, Beltrame F, et al. Evaluation of patient skin breakdown and comfort with a new face mask for non-invasive ventilation: a multi-center study. Intensive Care Med 2002;28(3):278-84.

7. Kernick L, Maqarey J. What is the evidence for the use of high flow nasal cannula oxygen in adult patients admitted to critical care units? A systematic review. Aust Crit Care 2010;23(2):53-70.

8. Parke R, McGuinness S, Eccleston M. Nasal high-flow therapy delivers low level positive airway pressure. Br J Anaesth 2009;103(6):886-90.

9. Roca O, Riera J, Torres F, Masclans JR. High-flow oxygen therapy in acute respiratory failure. Respir Care 2010;55(4):408-13.

10. Chatila W, Nugent T, Vance G, Gaughan J, Criner GJ. The effect of high-flow vs low-flow oxygen on exercise in advanced obstructive airways disease. Chest 2004;126(4):1108-15.

11. Rea H, McAuley S, Jayaram L, Garrett J, Hockey H, Storey L, et al. 
The clinical utility of long-term humidification therapy in chronic airway disease. Respir Med 2010;104(4):525-33.

12. Parke RL, Eccleston ML, McGuinness SP. The effects of flow on airway pressure during nasal high-flow oxygen therapy. Respir Care 2011;56(8):1151-5.

13. Wilkinson D, Andersen C, O’Donnell CP, De Paoli AG. High flow nasal cannula for respiratory support in preterm infants. Cochrane Database Syst Rev 2011;11(5):CDoo6405.

14. Sztrymf B, Messika J, Bertrand F, Hurel D, Leon R, Dreyfuss D, Ricard DJ. Beneficial effects of humidified high flow nasal oxygen in critical care patients: a prospective pilot study. Intensive Care Med 2011;37(11):1780-6.

15. Parke RL, McGuinness SP, Eccleston ML. A preliminary randomized controlled trial to assess effectiveness of nasal high-flow oxygen in intensive care patients. Respir Care 2011;56(3):265-70.

16. Tiruvoipati R, Lewis D, Haji K, Botha J. High-flow nasal oxygen vs high-flow face mask: A randomized crossover trial in extubated patients. J Crit Care 2010;25(3):463-8.

17. Groves N, Tobin A. High flow nasal oxygen generates positive pressure in adult volunteers. Aust Crit Care 2007;20(4):126-31.

18. Corley A, Caruana LR, Barnett AG, Tronstad O, Fraser JF. Oxygen delivery through high-flow nasal cannulae increase end-expiratory lung volume and reduce respiratory rate in post-cardiac surgical patients. $\mathrm{Br} \mathrm{J}$ Anaesth 2011;107(6):998-1004.

19. Dysart K, Miller TL, Wolfson MR, Shaffer TH. Research in high flow therapy: mechanisms of action. Respir Med 2009;103(10):1400-5.

20. Sasaki H, Yamakage M, Iwasaki S, Mizuuchi M, Namiki A. Design of oxygen delivery systems influences both effectiveness and comfort in adult volunteers. Can J Anaesth 2003;50(10):1052-5. 
21. Manley BJ, Owen LS, Doyle LW, Andersen CC, Cartwright DW, Pritchard MA, et al. High-flow nasal cannulae in very preterm infants after extubation. N Engl J Med 2013;369(15):1425-33.

Table 1. Characteristics of nine patients who received NHF therapy after liberation from NIV.

\begin{tabular}{|c|c|c|c|c|c|c|}
\hline \multicolumn{4}{|c|}{ No Age Sex BMI Diagnosis } & \multirow{2}{*}{$\begin{array}{l}\text { SOFA } \\
\text { score } \\
8\end{array}$} & \multirow{2}{*}{$\begin{array}{l}\text { Duration } \\
\text { of NIV } \\
\text { (day) } \\
2\end{array}$} & \multirow{2}{*}{$\begin{array}{l}\text { Duration } \\
\text { of NHF } \\
\text { (day) } \\
2\end{array}$} \\
\hline 1 & 79 & $\mathrm{~F}$ & 14.6 Post AVR & & & \\
\hline 2 & 82 & $\mathrm{~F}$ & 29.8 Post AVR & 15 & 6 & 1 \\
\hline 3 & 83 & M & $\begin{array}{l}\text { Post CABG and } \\
\text { MVR }\end{array}$ & 8 & 2 & 2 \\
\hline 4 & 74 & $\mathrm{~F}$ & 19.1 Post AVR & 9 & 2 & 4 \\
\hline 5 & 84 & M & 18.1 Post gastrectomy & 8 & 6 & 3 \\
\hline 6 & 60 & M & $\begin{array}{l}\text { Post ascending } \\
22.6 \text { aorta } \\
\text { replacement }\end{array}$ & 6 & 2 & 4 \\
\hline 7 & 72 & $\mathrm{~F}$ & 20.8 Post PCI & 7 & 3 & 1 \\
\hline 8 & 74 & $\mathrm{~F}$ & 29.6 Post CABG & 13 & 2 & 1 \\
\hline 9 & 70 & M & $\begin{array}{l}\text { Post CABG and } \\
\text { AVR }\end{array}$ & 11 & 2 & 1 \\
\hline
\end{tabular}

AVR, aortic valve replacement; BMI, index; CABG, coronary artery bypass graft; F, female; M, male;

MVR, mitral valve replacement; NHF, nasal high flow; NIV, non-invasive ventilation; PCI, percutaneous coronary intervention;

SOFA score, sequential organ failure assessment score.

Table 2. Changes in respiratory parameters after liberation from NIV. 


\begin{tabular}{|c|c|c|c|c|c|c|}
\hline & $\begin{array}{l}\text { NHF } \\
\text { group } \\
(n=9)\end{array}$ & $\begin{array}{l}\text { Historica } \\
\text { control } \\
\text { group } \\
(n=8)\end{array}$ & & & & \\
\hline & $\begin{array}{l}\mathrm{P} / \mathrm{F} \\
\text { ratio } \\
(\mathrm{mmHg})\end{array}$ & $\begin{array}{l}\mathrm{RR}( \\
/ \mathrm{min})\end{array}$ & $\begin{array}{l}\mathrm{P} / \mathrm{F} \\
\text { ratio } \\
(\mathrm{mmHg})\end{array}$ & $\begin{array}{l}\mathrm{RR} \\
( \\
/ \mathrm{min})\end{array}$ & & \\
\hline No & Before & After & Before & After & Before After Before & After \\
\hline 1 & 204 & 188.2 & 22 & 22 & 239.6218 .422 & 18 \\
\hline 2 & 291.4 & 296.2 & 23 & 22 & $306.8195 \quad 20$ & 24 \\
\hline 3 & 287.5 & 236.5 & 21 & 16 & 245.8208 .422 & 25 \\
\hline 4 & 207.6 & 211.8 & 20 & 20 & 364.8207 .816 & 19 \\
\hline 5 & 212.6 & $193 \cdot 4$ & 20 & 22 & $166 \quad 152.422$ & 26 \\
\hline 6 & 252.6 & 211.4 & 18 & 24 & $245 \quad 188.218$ & 20 \\
\hline 7 & $265 \cdot 3$ & 310 & 22 & 22 & $233.2 \quad 186.223$ & 26 \\
\hline 8 & 292.5 & 248.5 & 20 & 18 & $245.8 \quad 198.324$ & 22 \\
\hline 9 & 242.5 & 183.4 & 23 & 21 & & \\
\hline $\begin{array}{l}\text { mea } \\
\pm \\
\text { SD }\end{array}$ & $\begin{array}{l}250.7 \\
\pm \\
34.2\end{array}$ & $\begin{array}{l}231 \pm \\
43.6\end{array}$ & $\begin{array}{l}21 \pm \\
1.6\end{array}$ & $\begin{array}{l}20.8 \\
\pm \\
2.3\end{array}$ & $\begin{array}{lll}255.9 & 194.3 & \\
\pm & \pm & 20.9 \pm 2 . \\
58.1 & 20.1^{*} & \end{array}$ & $20.9 \pm 2.722 .5 \pm 3.2$ \\
\hline \multicolumn{7}{|c|}{$*: p=0.013$ compared with before } \\
\hline \multicolumn{7}{|c|}{$\begin{array}{l}\text { NHF, nasal high flow; NIV, non-invasive ventilation; } \mathrm{P} / \mathrm{F} \text { ratio, partial } \\
\text { pressure of arterial oxygen }\left(\mathrm{PaO}_{2}\right) \text { to fraction of inspiratory oxygen }\end{array}$} \\
\hline
\end{tabular}

Takuya Kurazumi, Rie Wakamiya, Kikuko Suga, Yoshihisa Morita, Junichi Masuda Department of Anesthesia, Kawasaki Municipal Hospital, Kawasaki, Japan

Takeshi Suzuki, Shizuko Kosugi, Nobuyuki Katori, Hiroshi Morisaki Department of Anesthesiology and General Intensive Care Unit, Keio University School of Medicine, Tokyo, Japan 
Correspondence:

Takeshi Suzuki

Department of Anesthesiology, Keio University School of Medicine

35 Shinanomachi, Shinjuku-ku, Tokyo 160-8582, Japan

Phone: +81-3-5363-3810

Fax: +81-3-3356-8439

E-mail: takeshi-su@a7.keio.jp

Article printed from Signa Vitae: http://www.signavitae.com

URL to article: http://www.signavitae.com/2016/o5/beneficialeffects-of-nasal-high-flow-oxygen-therapy-after-weaningfrom-non-invasive-ventilation-a-prospective-observationalstudy/

Copyright (C) 2015 Signa Vitae. All rights reserved. 